Epiphany: Vol. 7, No. 1, 2014

ISSN 1840-3719

\title{
REACHING OUT: SOCIAL SUPPORT AND MENTAL HEALTH PROBLEMS OF BOSNIAN IMMIGRANTS IN SWITZERLAND
} Selvira Draganović ${ }^{*}$

\begin{abstract}
A state of well being in which one realizes own potentials, can cope with every day stressors, can work productively and is able to constructively contribute to community is called mental health. Many stressful and negative events can interfere with these abilities and thus endanger someone's mental health. Migration is one of them. With its' pre and post phases/stages, migration represents great sources of stress and stressors. Immigrants need good personal and social resource in order to lessen down negative effects of migration on their mental health. The aim of this study is to explore presence of mental health problems in non clinical population of Bosnian immigrants $(\mathrm{N}=101$, $\mathrm{F}=48, \mathrm{M}=53$ ) in Switzerland. It was assumed that migration stress acts negatively on immigrant's mental health. General health questionnaire was used to test this hypothesis. Participants mean score results on total GHQ28 questionnaire were $\mathrm{M}=51.06$, S.D. $=14.30$, its subscales on depression $\mathrm{M}=10.12$ S.D. $=3.75$, somatic complaints $\mathrm{M}=13.04$ S.D. $=4.5$, anxiety/insomnia $\mathrm{M}=13.34$ S.D. 4.8, and social dysfunction $\mathrm{M}=14.37$ S.D.=3.5. This indicates presence of mental health problems among Bosnian immigrants. At the same time, the study shows presence of social support seeking ( $\mathrm{N}=83$ subjects listed family and friends) as primary coping strategy used by Bosnian immigrants while dealing with difficulties and problems rather than seeking professional help ( $\mathrm{N}=3$ subjects listed professional help seeking). Thus, social support seeking acts positively on mental health of Bosnian immigrants.
\end{abstract}

Keywords: Mental Health; Immigrants; Bosnian Immigrants; Social Support

\footnotetext{
* Corresponding author: Selvira Draganović, PhD Candidate, Faculty of Philosophy, University of Sarajevo; e-mail: selvirad@ hotmail.com
} 


\section{Background to the study}

According to Kakar (Fernando, 2001) concept of mental health is

a term which covers different aspects and concerns such as: absence of disabling symptoms, integration of psychological functioning, successful leading of personal and social life, and feeling of ethical and spiritual wellbeing. However, for our purpose, mental health defined as the ability to think logically and rationally, to adjust to transitions, stress, trauma and losses which happen to everyone, in a way which allows emotional stability and growth, suites better (Hales and Hales, 1995).

Immigrants belong to a risk group for mental health disorders due to many pre emigrational, emigrational as well as post emigrational factors and phases that they go through. Acculturation phases, adjustment, immigrants' age as well as effects of factors such as small income, immigrants' status, low access to psychiatric treatment etc, are in close relation to the emergence of mental health problems like depression, anxiety, suicide, alcohol and drug use by immigrants. Immigrants are at risk for mental health problems due to much pre-migration, migration as well post migration factors and phases which 

S. Draganović Social Support and Mental Health Problems of Bosnian Immigrants
immigrants experience. Acculturation phase, adjustment, immigrants' age, interrelated factors such as low income, immigrants' status, low access to psychiatric care etc. are related to appearance of mental health problems such as depression, anxiety, suicide, and alcohol and drug abuse in immigrants' population. Immigrants are risk population especially when they migrate with low or no prior knowledge about country they migrate to. Their coping strategies are not always efficient and acceptable. Coping strategies represent immigrant's efforts, mainly psychological and behavioural, which immigrants use, tolerate, decrease or minimize stressful events. Lazarus and Folkman (Horwitz and Scheid, 2006) coping strategies define as cognitive or behavioural attempts to cope with situational demands that someone perceives demanding or those that overcome someone's ability to cope. In other words, coping is actually a process by which people try to cope with perceived difference between demands and own resources which they assess in a given situation. People cope with certain problems by making certain efforts in order to adjust to a problem or change their perception about it. As such, these efforts could be effective 201 Epiphany: Journal of Transdisciplinary Studies, Vol. 7. No. 1, (2014) ๑ Faculty of Arts and Social Sciences 
S. Draganović Social Support and Mental Health Problems of Bosnian Immigrants (seeking social support for example) or ineffective (avoiding problems) leading to problems solving or the opposite.

Effective coping strategies in a form of social support can decrease effects of permanent stressors and act positively on immigrants' mental health. On contrary, ineffective coping strategies which could appear in a form of avoidance or retreat when different stressors appear, contribute to emergence of mental health problems (Busse and O'Mahoney, 2000). Coping strategies are usually divided into primary and secondary coping strategies and problem focused and emotion focused coping strategies. Primary coping strategies are direct measures or, overt, problem focused behaviour directed to change of disturbing events in stressful environment (looking for social support). Unlike primary, secondary coping strategies are more cognitive than behavioural and they are most often related to changing perception and assessment of stressful situations and events. In another words, primary coping strategies mean changing environment so it will suite "me" and secondary, changing "me" so I will suit the environment.

\footnotetext{
Epiphany: Journal of Transdisciplinary Studies, Vol. 7. No. 1, (2014) @ Faculty of Arts and Social Sciences
} 
S. Draganović Social Support and Mental Health Problems of Bosnian Immigrants

Looking for social support contributes to adjustment and helps individuals to easily cope with problems because persons with social support are emotionally more stable and cope with different environmental demands as well as with mental health problems more easily (Horwitz and Scheid, 2006).

Social support is related to someone's social contacts and relations, social integration and relation inside primary group. Social support and relations (resources) and relations with others from where support emerges are not only basis for mental health but also can serve as protective factors from negative effects of different stressors. Resources or sources of coping (social support, strong felling of control etc.) and coping strategies reduce or diminish negative psychological effects of stress and stressors (Horwitz and Scheid, 2006).

Horwitz and Sheid (2006) cite many studies which researched significance of relation between mental health and social support (Cohen and Willis, 1985; Cohen and Syme, 1985; Dean and Lin 1977; Gottlieb, 1981; Kessler et all 1985; Sarason and Sarason, 1985; Sarason, Sarason and Pierce, 1990; Turner 1983; Vaux 1988; Veil and Bauman, 1992) and great majority of these studies 
S. Draganović Social Support and Mental Health Problems of Bosnian Immigrants shows great correlation with little or no support and ill mental health in general, especially with frequent depression. Cassel and Cobb with their research have set preliminary foundation for hypothesis which dominates inside these researches: "social support is important moderator in effects of life stressors on mental health" and as such it represents significant protective factor (Horwitz and Scheid, 2006). Ward states that social support is related to improvement of psychological wellbeing (greater social support, better psychological wellbeing and vice versa) (Ward, Bochner and Furnham, 2003). Besides, sociological studies in domain of social support suggest abating effect of psychological problems when there is strong or just present social support regardless if it comes from ethnic community or local citizens (Khuo and Tsai, 1986).

Aim of this study is to explore presence and role of social support in mental health problems in non clinical population of Bosnian immigrants in Switzerland. It was assumed that social support has a role in mental health of Bosnian immigrants in Switzerland. 


\section{Participants and methods}

Participants

Participants $(\mathrm{N}=200)$ were 48 female and 53 male, ages between 18 and 60, Bosnian immigrants currently residing in Switzerland.

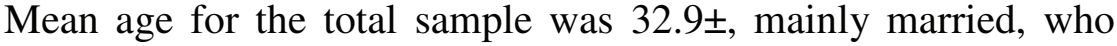
migrated to Switzerland in three periods, before the war (19921995), during the war, after the war. Out of total number 129 surveys were completed and delivered to researcher. 28 of them could be only partially used due to incomplete data (demographics or unanswered questions. Participants were generally healthy and were not cognitively or perceptually impaired. They were recruited from a large Bosnian community in Switzerland.

\section{Procedure}

Participation in the study was voluntary and no compensation was given. The survey, entitled "Mental Health," consisted of sociodemographic questionnaire and general health questionnaire GHQ 28.

\section{Questionnaires}

Demographic questionnaire, and participants demographics: A few independent variables stated as important predictors which act positively on mental health of immigrants, as proved by former 
S. Draganović Social Support and Mental Health Problems of Bosnian Immigrants studies and report, were also included in our study: gender, marital status, age, year of migration, immigrants status - visa type (B visa - resident and work permit for a year -can be prolonged, or $\mathrm{C}$ visa - permanent work and resident permit or $\mathrm{CH}$ visa - Swiss citizenship, employment before migration, current employment, length of residency in Switzerland.

General health questionnaire 28 (GHQ 28) (widely used for similar purposes by, Jancz, 2000, for example).

General health questionnaire 28 (GHQ 28): For the purpose of this research we used general health questionnaire with 28 items, shortened version of GHQ with 60 items. General health questionnaire 28 (GHQ 28) is a multiple choice paper pen questionnaire. It is designed to detect current non psychotic psychiatric disorders in general population. Questionnaire has four subscales: Somatic complaints, anxiety and insomnia, social dysfunction, major depression.

General health questionnaire can be administered to adolescents or adults of any age. It is diagnostic but it can be used to detect acute conditions (Goldberg and Hillier, 1979). Since 1972 when Goldberg first created its' first version with 140 items, general 
S. Draganović Social Support and Mental Health Problems of Bosnian Immigrants health questionnaire was translated to 38 world languages (Croatian is one of them, which we used) it has been validated in more than 50 studies. There are four versions of it at the moment (with 60, 30, 28 and 12 items) available to psychiatrists, qualified doctors, clinical psychologists and experienced counsellors (Jancz, 2000). Cronbach's (1951) alpha coefficient for internal validity for GHQ 28 version ranges from .84 to .93 in different studies. Goldberg and Hillier (1979) cite that test - retest probability coefficient on 87 psychiatric cases with six months follow up was .90 and it appears as reliable and valid assessment technique for psychological or mental health (Jancz, 2000). Results for general health questionnaire (GHQ 28) are gained by adding responses on all items and summing them up. Higher score implies more mental health problems in form of depression, anxiety, somatic complaints or social dysfunction.

These two parts were completed with two open ended questions: 1. Who do you talk to about your problems/difficulties, 2. Who do you seek to share or talk to when you face any kind of problems/difficulties. 
S. Draganović Social Support and Mental Health Problems of Bosnian Immigrants

Analysis and categorisation of respondents' answers to the two, above cited open ended questions, indicate four following categories: family and friends, professionals, myself and no one.

\section{Results}

We used General Health Questionnaire 28 in order to test presence of mental health problems among Bosnian immigrants in Switzerland. Results of means and standard deviations are listed in table below.

\begin{tabular}{|l|r|r|r|r|r|}
\hline $\begin{array}{l}\text { General health questionnaire } \\
\text { GHQ 28 }\end{array}$ & N & Minimum & Maximum & \multicolumn{1}{c|}{ Mean } & Std. Deviation \\
\hline Results on somatic & 98 & 7,00 & 24,00 & 13,0408 & 4,51097 \\
complaints subscale & 100 & 7,00 & 28,00 & 13,3400 & 4,88911 \\
$\begin{array}{l}\text { Results on anxiety insomnia } \\
\text { subscale }\end{array}$ & 96 & 7,00 & 25,00 & 14,3854 & 3,59933 \\
$\begin{array}{l}\text { Results on social dysfunction } \\
\text { subscale }\end{array}$ & 93 & 7,00 & 24,00 & 10,1290 & 3,75391 \\
$\begin{array}{l}\text { Results on depression } \\
\text { subscale }\end{array}$ & 87 & 28,00 & 91,00 & 51,0690 & 14,30547 \\
GHQ total results & 78 & & & & \\
Valid N (listwise) & & & & & \\
\hline
\end{tabular}

Table 1. Mean results on GHQ and its subscales

Table 2 two shows most frequently cited answers to question

"Who do talk to - share your problems with?

\begin{tabular}{|c|c|c|c|c|c|}
\hline & & Frequency & Percent & $\begin{array}{l}\text { Valid } \\
\text { Percent }\end{array}$ & $\begin{array}{c}\text { Cumulative } \\
\text { Percent }\end{array}$ \\
\hline \multirow[t]{5}{*}{ Valid } & Family and friends & 83 & 82,2 & 84,7 & 84,7 \\
\hline & professionals & 3 & 3,0 & 3,1 & 87,8 \\
\hline & No one & 11 & 10,9 & 11,2 & 99,0 \\
\hline & myself & 1 & 1,0 & 1,0 & 100,0 \\
\hline & Total & 98 & 97,0 & 100,0 & \\
\hline Missing & System & 3 & 3,0 & & \\
\hline Total & & 101 & 100,0 & & \\
\hline
\end{tabular}


Table 3 shows most frequently cited answers to question "Who do you turn to/ask/ for advice and help when faced with difficulties and problems?

\begin{tabular}{|c|c|c|c|c|c|}
\hline & & Frequency & Percent & $\begin{array}{c}\text { Valid } \\
\text { Percent }\end{array}$ & $\begin{array}{c}\text { Cumulative } \\
\text { Percent }\end{array}$ \\
\hline \multirow[t]{4}{*}{ Valid } & \multirow{2}{*}{$\begin{array}{l}\text { Family and } \\
\text { friends } \\
\text { Professionals }\end{array}$} & 79 & 78,2 & 81,4 & 81,4 \\
\hline & & 7 & 6,9 & 7,2 & 88,7 \\
\hline & \multirow{4}{*}{$\begin{array}{l}\text { No one } \\
\text { Total } \\
\text { System }\end{array}$} & 11 & 10,9 & 11,3 & 100,0 \\
\hline & & 97 & 96,0 & 100,0 & \\
\hline \multirow{2}{*}{$\begin{array}{l}\text { Missing } \\
\text { Total }\end{array}$} & & 4 & 4,0 & & \\
\hline & & 101 & 100,0 & & \\
\hline
\end{tabular}

To test the the difference for variable: talking with family and freinds, and GHQ 28 and its subscales ANOVA test of variance. Results are presented in table below.

\begin{tabular}{|c|c|c|c|c|c|c|}
\hline $\begin{array}{l}\text { Variable: who do you } \\
\text { talk with about your } \\
\text { problems/difficulties? } \\
\text { Participants-answered } \\
\text { Family and friends }\end{array}$ & Variability source & Sum squares & df & Variance & $\mathrm{F}$ ratio & Sig. \\
\hline $\begin{array}{l}\text { General health } \\
\text { questionnaire (GHQ } \\
28)\end{array}$ & $\begin{array}{l}\text { Between groups } \\
\text { Within groups } \\
\text { Total variability }\end{array}$ & $\begin{array}{c}3625,568 \\
13691,208 \\
17316,776\end{array}$ & $\begin{array}{c}3 \\
81 \\
84\end{array}$ & $\begin{array}{c}1208,523 \\
169,027\end{array}$ & 7,150 & ,000 \\
\hline $\begin{array}{l}\text { GHQ-subscale somatic } \\
\text { complaints }\end{array}$ & $\begin{array}{l}\text { Between groups } \\
\text { Within groups } \\
\text { Total variability }\end{array}$ & $\begin{array}{c}122,829 \\
1820,911 \\
1943,740\end{array}$ & $\begin{array}{c}3 \\
92 \\
95\end{array}$ & $\begin{array}{l}40,943 \\
19,793\end{array}$ & 2,069 &, 110 \\
\hline $\begin{array}{l}\text { GHQ-subscale social } \\
\text { dysfunction }\end{array}$ & $\begin{array}{l}\text { Between groups } \\
\text { Within groups } \\
\text { Total variability }\end{array}$ & $\begin{array}{c}307,292 \\
903,826 \\
1211,118\end{array}$ & $\begin{array}{c}3 \\
89 \\
92\end{array}$ & $\begin{array}{c}102,431 \\
10,155\end{array}$ & 10,086 & ,000 \\
\hline $\begin{array}{l}\text { GHQ-subscale anxiety } \\
\text { and insomnia }\end{array}$ & $\begin{array}{l}\text { Between groups } \\
\text { Within groups } \\
\text { Total variability }\end{array}$ & $\begin{array}{c}181,622 \\
2141,644 \\
2323,265\end{array}$ & $\begin{array}{c}3 \\
94 \\
97\end{array}$ & $\begin{array}{l}60,541 \\
22,783\end{array}$ & 2,657 &, 053 \\
\hline $\begin{array}{cc}\begin{array}{c}\text { GHQ- } \\
\text { depression }\end{array} & \text { Subscale }\end{array}$ & $\begin{array}{l}\text { Between groups } \\
\text { Within groups } \\
\text { Total variability }\end{array}$ & $\begin{array}{l}1432,382 \\
7483,573 \\
8915,956\end{array}$ & $\begin{array}{c}2 \\
87 \\
89\end{array}$ & $\begin{array}{c}716,191 \\
86,018\end{array}$ & 8,326 &, 000 \\
\hline
\end{tabular}

Epiphany: Journal of Transdisciplinary Studies, Vol. 7. No. 1, (2014) @ F Faculty of Arts and Social Sciences 
S. Draganović Social Support and Mental Health Problems of Bosnian Immigrants

Significance $\mathrm{p}<0.05$

Table 4. ANOVA variance test results for variable talking with family and friends and GHQ, and its subscales: somatic complaints and social disfunction. Note: Significant results are emboldened.

\section{Discussion}

As presented in tables above, mean scores results on GHQ 28 and it's subscales, indicate mild presence of mental health problems (Mean scores=51.07, s.d. 14.31). Social dysfunction scale points to the highest mean scores results, Mean=14.3854, s.d. 3.593). ANOVA results point significant difference on variable talking with family and friends and general health questionnaire GHQ 28, its' social dysfunction and depression subscales. F-ratio is, 7.15 (with $\mathrm{p}=.000), 10.09(\mathrm{p}=.000)$, and $8.33(\mathrm{p}=.000)$ respectively. Considering stressful effects of migration and adjustment processes this results are not surprising. However, in answer to the open ended questions "who do you talk to/who do you seek to talk with when faced with problems", most frequently cited response was "family and friends (before professionals). This response indicates strong presence of social support, good social 
S. Draganović Social Support and Mental Health Problems of Bosnian Immigrants networking, and reaching out as coping strategy which Bosnian immigrants use. Reaching out and seeking social support and networking, which appears in a form of the need for instant/immediate talk with family/friends during and after problems (and personal distress) incessant phenomena within Bosnian community. Stressful and problematic situations have to be shared and discussed right away (Bosnian call this "a cup of talk", a talk while drinking coffee or some other drink). Such encounters have many positive outcomes. Firstly, utmost important for immigrant's mental health is a strong sense of emotional relief which follows this "cup of talk" or layman's therapeutic sessions (immediate sharing/discussion of problems). Secondly, reaching out and social support seeking results in diminishing of short and long term stressful issues and problems. Still, sharing problems with others results in short stress relief. Operational definition of migration in our paper is based on the fact that migration is closely related with psycho social process of loss and change as well as adjusting to a number of stressors. In psychiatric terminology loss is linked to the grieving process (Carta, Bernal, Hardoy, Haro-Abad, 2005.) Grieving is reaction to

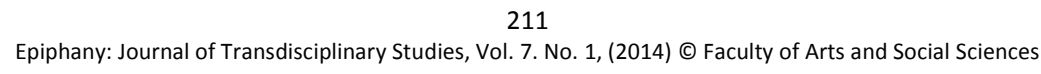


S. Draganović Social Support and Mental Health Problems of Bosnian Immigrants

a specific psychosocial stressor (a loss of a loved one for example) but it is not considered as psychological disorder. However, if grieving is severe or prolonged more than it should be, then it belongs to the category of major depressive disorder or adjustment disorder (First, Frances and Pincus, 1997).

This grieving process during migration is explained through seven stages which cause anxiety and distress in immigrants: family, friends, language, culture, homeland, loss of status, loss of contact with ethnic group and exposure to the physical risks (Carta, Bernal, Hardoy and Haro-Abad, 2005). Above this, researchers consider that this emigrational grieving is interrupted/discontinuous because sources of grieving disappear during the contact with homeland and appear again after the return. This is not the case with grieving for the loss of the loved one which is continuous process (contact with a person completely ceased due the death). Thus, host country acceptance is of crucial importance in this case because difficulties in showing the grief might cause many psychological problems. The loss of contact with family and friends, loss of status, adapting to the new language, culture, environment and all the

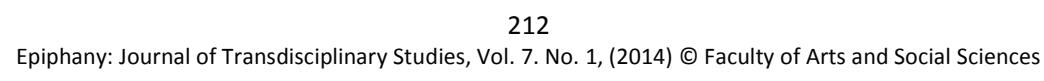


S. Draganović Social Support and Mental Health Problems of Bosnian Immigrants other inevitable changes in a process of immigration could be huge sources of anxiety, distress and stress thus endangering immigrant's mental health. At the same time, regardless of the country's politics, citizens in some countries fiercely react to foreigners and as a result discrimination, xenophobia, racism, and different stereotypes appear. Problems which arise as a result of such reactions make immigrant's adjustment difficult and may cause adjustment disorders.

\section{Conclusion}

Even though social support is one of the coping strategies most often used by Bosnian immigrants in Switzerland, which according to many studies, proves to serve as mediator in manifestation and occurrence of mental health problems, it seems that solely it does not serve the purpose. Our results, in line with other studies, indicate that migration stress acts negatively on mental health of immigrants. Mean scores on GHQ 28 show that Bosnian immigrants suffer from mild stress, depression, anxiety, somatic complaints, insomnia and social dysfunction. ANOVA ttest for variance also shows significant results for variable "talking with family and friends "and General health Epiphany: Journal of Transdisciplinary Studies, Vol. 7. No. 1, (2014) @ Faculty of Arts and Social Sciences 
questionnaire GHQ 28 and its social dysfunction and depression subscales.

Family and friends are most frequently sought source of support among Bosnian immigrants. This speaks of immigrants' two very important coping factors: integration and assimilation. Integration means shaping up own identity by nurturing own traditional values (ethnic country) and adopting cultural traditions of host country. Assimilation is a process which contains three basic elements: learning and adopting new reactions to the host society, irretrievable changes related to adoption and acceptance of cultural, historic and intellectual forms of new, host society and finally, transformation into a full social member of a given new society. Strong social support from family and friends of Bosnian immigrants in Switzerland could mean strong social networking made of members of own ethnicity what indicates confinement inside own ethno group and weak or no integration and assimilation.

Weak or no integration and assimilation, on the other side, means weak acceptance by host society and adjustment to it, what in turn can result in psychological maladjustment, feeling of being 
S. Draganović Social Support and Mental Health Problems of Bosnian Immigrants discriminated, feeling of being a citizen of second order, feeling of not belonging there, feeling rejected and unwanted. Perceived discrimination is related to increased psychological distress and pain (Furnham and Shiek, 1993, Ying, 1996). Such feelings form solid basis for immigrants' even greater wish to close up and remain within own ethno-group. Members of their own ethnogroup understand one another and have the same or similar problems. This leads to immigrants need to meet and associate even more often and discuss their problems. In the end, although they talk about their problems and social support as coping strategy is strongly present, strong feelings of not belonging, discrimination and rejection might still cause distress. Thus, mental health problems might appear showing that immigrants are vulnerable and at risk to develop mental health problems.

Finally, this study indicates that Bosnian immigrants turn to mental health professional little or not at all when they face problems or difficulties (only $10 \%$ or participants stated that they turn to mental health professionals when they face problems and difficulties). This data also indicates different beliefs about mental health and illness as well as treatment of mental disorders which 
S. Draganović Social Support and Mental Health Problems of Bosnian Immigrants is typical for Bosnian citizens who turn to mental health professional only as a last resort, when they exhaust all other ways and means. Stigma (mental health issues are still related to "being crazy/mad") related to mental disorders is still present among Bosnians, even when they live in society with different orientation towards mental health/disorders.

\section{References}

Beck A. T., Steer R. A., Garbin M. G. 1988. "Psychometric properties of BDI: twenty-five years of evaluation." Clinical Psychology Review.

Busse D., O'Mahoney G.P. 2000. Migration Issues in Mental Health: A Review; 1-er Congreso Virtuale Psiquiatria, February - Mart, inter Salud net.

Carta, M. G., Bernal, M., Hardoy, C. M. 2005. "Migration and mental health in Europe (the state of mental health in Europe working group)." Clin Pract Epidemiol Ment Health. 2005; 1: 13.

Cohen, Kamarck and Mermelstein. 1983. "A global measure of perceived stress." Journal of Health and social behavior; 24/4; $385-396$.

Fernando S. 1995. Mental Health in a Multi Ethnic Society: a Multidisciplinary Handbook. Routledge, UK.

Furnham, A., Sheikh, S. 1993. "Gender, generational and social support correlates of mental health in Asian immigrants." International Journal of Social Psychiatry 39:22-33

Goldberg, D. P., and Hillier, V. F. 1979. "A scaled version of the General Health Questionnaire." Psychological Medicine, 9, 139-145.

Hales, D., and Hales, R. E. 1995. Caring for the Mind: The Comprehensive Guide to Mental Health. Bantam Books, New York

Horwitz A. V., Scheid T. L. 1999. A Handbook for the study of Mental Health: Social Context, theories and systems._Cambridge University press, UK. 
S. Draganović Social Support and Mental Health Problems of Bosnian Immigrants

Jancz M. 2000. Social and psychological adjustment of first generation Polish Immigrants to Australia. University of Sidney. Sidney.

Kuo W. H.; Tsai Y. M. 1986. "Social networking, hardiness and Immigrant's Mental health." Journal of health and social behaviour. vol. 27; 2, 133-149.

Lazarus R., Folkman S. 1984. Stress, appraisal and coping. Springer Publishing Company, New York.

Ward C., Bachner S., Furuhan A. 2001. The psychology of culture shock. Routledge, United Kingdom. 